\title{
How are Child-Specific Utility Instruments Used in Decision Making in Australia? A Review of Pharmaceutical Benefits Advisory Committee Public Summary Documents
}

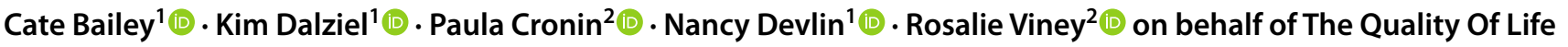 \\ in Kids: Key Evidence to Strengthen Decisions in Australia (QUOKKA) Project Team
}

Accepted: 13 October 2021 / Published online: 5 November 2021

(c) The Author(s) 2021

\begin{abstract}
Measuring and valuing health-related quality of life (HRQOL) in children can be challenging but is an important component for providing decision makers with accurate information to fund new interventions, including medicines and vaccines for public subsidy. We review funding submissions of medicines made to the Pharmaceutical Benefits Advisory Committee contained in public summary documents to examine the use of child-specific HRQOL measures in decision making in Australia. A sample frame of medicines used by children was derived from four sources. Public summary documents relating to these medicines were searched in the Pharmaceutical Benefits Advisory Committee web resources for whether they related to children (aged under 18 years) and contained HRQOL information and/or cost-utility analyses. Data about the use of utilities in decision making were extracted and analysed. Of the 1889 public summary documents available, 62 public summary documents (29 medicines) contained information pertaining to children and utilities. Of these, four public summary documents included child-specific HRQOL measures, 16 included adult HRQOL measures, 11 included direct elicitation and the HRQOL source was not defined in 31 documents. Excluding documents using child-specific HRQOL measures, we considered that in $85 \%$ of medicines, decision making uncertainty might have been reduced by using child-specific HRQOL measures. Despite the growing literature on economic analysis in paediatric populations, the use of child-specific HRQOL measures in submissions to the Pharmaceutical Benefits Advisory Committee was minimal. Submissions involved inconsistent approaches, use of adult measures and weights, and substantial gaps in evidence. We recommend the consistent use of child-specific measures to improve the evidence base for decisions about medicines for children in Australia.
\end{abstract}

How are child-specific utility instruments used in decision making in Australia? A review of Pharmaceutical Benefits Advisory Committee public summary documents (MP4 $24905 \mathrm{~kb}$ )

Cate Bailey

cate.bailey@unimelb.edu.au

1 Health Economics Unit, Melbourne School of Population and Global Health, University of Melbourne, 207 Bouverie St, Carlton 3053 Melbourne, VIC, Australia

2 Centre for Health Economics, Research and Evaluation (CHERE), University of Technology Sydney, Sydney, NSW, Australia
Digital Features for this article can be found at https://doi.org/ 10.6084/m9.figshare.16807063

\section{Key Points for Decision Makers}

We investigated the use of child-specific utility measures in decision making in Australia through a review of Pharmaceutical Benefits Advisory Committee public summary documents.

The use of child-specific utilities in Pharmaceutical Benefits Advisory Committee recommendations was minimal.

Consistent use of child-specific utility measures would improve the evidence base for decisions about medicines for children in Australia. 


\section{Introduction}

Measuring and valuing health-related quality of life (HRQOL) is an essential part of economic evaluation in healthcare, allowing estimation of quality-adjusted life-years (QALYs) to compare outcomes and value for money across different populations, health conditions and interventions [1,2]. Although methods for measuring and valuing HRQOL are widely used and accepted in adults, these measures were not designed for use in children (persons aged under 18 years) [3]. Questions included in adult measures may be unsuitable for children's age and stage of development, and need to be appropriate if children are asked to self-report their own health [4]. Stated preference tasks to value health need to be conceptualised differently from those of adults to be appropriate for children's cognition and abilities, and this is particularly important when measuring on a scale anchored between death and full health, such as in time trade-off and standard gamble techniques [5]. Nonetheless, decision makers need to make judgements on the allocation of resources to interventions for children and adolescents to maximise the efficient allocation of healthcare provisions across the population, necessitating the development of child-specific utility measures with relevant dimensions [6].

In Australia, the Pharmaceutical Benefits Advisory Committee (PBAC) recommends which medicines and vaccines will be subsidised through the Pharmaceutical Benefits Scheme (PBS) [7], and evidence generated from measures of HRQOL form part of the information used to make these recommendations. The PBS is an Australian Governmentfunded scheme that provides subsidised access to medicines for the Australian population, with recommendations about what medicines are listed on the PBS being made based on an evaluation of evidence about comparative safety, effectiveness, cost effectiveness and budget impact. A summary of submissions to the Committee and the Committee's considerations are provided publicly through public summary documents (PSDs) to provide transparency on determinations made by the Committee. The PSDs are available on the Australian Government Department of Health website [8] and are searchable by submission. Each medicine may have multiple submissions prior to approval for the same medicine (i.e. multiple PSDs).

An economic evaluation typically forms part of the evidence used to inform recommendations by the PBAC, and may take the form of a cost-effectiveness analysis, cost minimisation analysis or cost-utility analysis. The PBAC guidelines indicate a preference for a cost-utility analysis over a cost-effectiveness analysis, where possible, as a cost-utility analysis facilitates comparison across interventions or medicines that have different impacts on health outcomes [9] (the guidelines emphasise justifying the choice of information contained in models but are not prescriptive about the choice of information included). A cost-utility analysis requires information about impacts on HRQOL, and a source of utility values (HRQOL weights) in order to generate QALYs.

When the PBAC considers a submission, it makes a recommendation to either list or not list the medicine on the PBS, or may defer the recommendation pending additional information. If a medicine is not recommended, a re-submission can be made for a future meeting, but it should address the reasons for the PBAC's initial rejection. In general, a decision not to recommend a submission in relation to a medicine is made based on uncertainty about the comparative clinical benefit or cost effectiveness. This uncertainty may relate to the clinical evidence, to the parameters of the economic model, or to how the medicine will be used in practice. It is important to note that a submission for listing is at a requested price, and therefore rejection may reflect that the PBAC did not consider the claim of clinical benefit or cost effectiveness was justified at that price.

Information about HRQOL included in the submission may be based on direct measures of patient-reported outcomes using an HRQOL instrument in a clinical trial or from information drawn from other sources (such as direct elicitation) [10]. The utility values (HRQOL weights) that are used to calculate the QALYs may be drawn directly from a multi-attribute utility instrument (a HRQOL instrument that has a scoring algorithm or set of weights derived from population-based preferences using a stated-preference task), or a transformation may have been conducted to provide utility values. The resultant QALY estimates are a key input to the denominator of the incremental costeffectiveness ratio that informs the PBAC's recommendations; therefore, issues around the appropriateness of the HRQOL measure or the utility values for the population under consideration can be a key source of uncertainty for the PBAC. The potential impact of this uncertainty is that the PBAC may not be able to determine whether cost effectiveness could be deemed acceptable even though the item may indeed provide clinical benefit and good value for money, or that it approves a medicine at a price that does not reflect value for money.

The PBAC PSDs are the most comprehensive public source of information on the PBAC's recommendations, and the "Recommendations and Reasons" section in the documents provides relevant information for key stakeholders (including manufacturers, clinicians and patients). Because of the confidential nature of some of the information in submissions to the PBAC, certain information is redacted from the PSDs (such as some information on the economic evaluation or the parameters selected for the model, including HRQOL information), particularly if this was not germane to the PBAC outcome. 
A central question regarding decision making for medicines used by children is how child HRQOL and child QALYs have been measured and valued. For example, have the clinical studies collected HRQOL information, and if so, was that information specific to children and were child-specific values used? [4]. Determining how best to answer questions about HRQOL for children are important, as expressed at the national level through a call for tools to value health change in paediatric populations in a recent funding opportunity through the Australian Government's Medical Research Future Fund [11].

In this review, we assess the information that is available in the PBAC PSDs about children's HRQOL and the associated utility values and estimated QALY gains. Public summary documents were chosen as the source of information for this review as they are publicly available, they reflect what the PBAC considered was appropriate to reveal about the submission and the recommendation (given that the original source documents are treated as confidential) and they provide a source of information for stakeholders about issues that are important in submissions. There were five specific research questions for the current review:

1. In how many of the PSDs for medicines and vaccines used by children were children mentioned specifically as a part of the population in question, and how many of these included cost-utility analyses?

2. What child-specific measures of HRQOL were used to estimate QALYs and how many recommendations were informed by evidence from child-specific measures of HRQOL?

3. How often were adult HRQOL measures used in decision making for children?

4. What other methods were used to determine HRQOL values?

5. To what extent did the valuation of HRQOL contribute to uncertainty in decision making?

In this study, we have shortened 'utility values' to 'utilities', and the terms utility, value, preferences and HRQOL weights are used interchangeably, although there are theoretical distinctions to be drawn between these concepts. For the purposes of this paper, we refer throughout to 'utilities' as any number used to summarise HRQOL specifically for the estimation of QALYs.

\section{Methods}

\subsection{Identification of Relevant PSDs}

We used four methods to construct a sample frame of medicines and vaccines to use in searching for relevant PBAC PSDs. First, we consulted the World Health Organization Model Lists of Essential Medicines for Children (most recent version, updated in June 2019) [12]. Medicines in this list are sourced through recommendations from the World Health Organization Expert Committee as being specifically used for children. The 2019 list contained a total of 336 essential medicines for children.

The second source for the sample was all recorded medicines used by children in the Longitudinal Study of Australian Children. The Longitudinal Study of Australian Children is a large study following approximately 10,000 young people's development across Australia, over two cohorts, every 2 years since 2003, with the current data collection at Wave 9 [13]. The sample used in the current study included data for all waves from 2003 to 2017, from both cohorts. Prior to 2012, drugs not attracting government payment (not subsidised by PBAC) were not included in the Longitudinal Study of Australian Children, and hence not included in our sample. The total number of medicines here was 389 . The third sample was sourced through the search engine on the PBAC site for the words: "child" or "adolescent" or "infant". The final source for the sample was the vaccines listed for children on the Australian National Immunisation Program [14].

\subsection{Procedure}

To determine the age of the population in each PSD identified in the sample frame, a search was conducted for the keywords: "child*", "adol*" (for adolescent), "aged", "juve*" (for juvenile) and "you*" (for young or youth) to determine whether there was reference in the PSD to the population under consideration (under 18 years of age). A search for "adult" was also conducted to find text that may define whether the population was specific to adults, and the text in relevant sections of the document was checked.

For each PSD, a second search was conducted to determine whether the document included a cost-utility analysis or any reference to HRQOL in the economic analysis, using the keywords "quality" and "QALY" and "utilit*" as well as checking the economic analysis and recommendation sections of the document. All PSDs where there was evidence that children or adolescents were considered as users of the medicine, and where a cost-utility analysis and/or QALYs were referred to, were retained for analysis. This search was double checked by the first author (CB) and 10\% of the sample was checked by the third author (PC). Cases where inclusion was unclear were discussed within the authorship team.

\subsection{Data Extraction}

Data were extracted for medicine name, meeting date, type of submission (initial, resubmission, expansion, change of listing, adjustment to schedule), condition, population age, comparator, 
the clinical claim, whether HRQOL was included in trial outcomes, type of economic analysis, time horizon, utility weights specific to children, whether sensitivity analysis was conducted on the utility values, incremental cost-effectiveness ratio range and the recommendation made by the PBAC. In a second extraction of the data conducted as a quality assurance exercise, we investigated the key concerns and issues raised, which elements the model was most sensitive to and key reasons for recommendations. Concurrently, we searched the Recommendation and Reasons section of the document for comments on whether the use of utility values for children had affected the recommendation regarding inclusion of the medicine in the PBS, and full text quotes were extracted.

\subsection{Data Analysis}

The search was documented using a diagram based on the Preferred Reporting Items for Systematic reviews and Meta-Analyses (PRISMA) [15]. The number of medicines and accompanying PSDs that mentioned a person under 18 years of age and included a cost-utility analysis or mention of QALYs or utilities was determined, and documents were organised into four categories: (1) where child-specific HRQOL measures were used, (2) where adult HRQOL measures were used, (3) direct elicitation techniques used to generate child-specific utility values, and (4) where the source of utility values was not defined.

For submissions where child utilities were not available or had not been used, we considered whether uncertainty could have been reduced through the use of child-specific utilities. This determination was made on the basis of: (a) if a cost-utility analysis was used in the recommendation, (b) whether the model was sensitive to the utility values and utility values were considered important, and (c) whether children were an important part of the population under consideration (i.e. if the medicine was commonly used for children rather than mostly used for adults). If all three factors were apparent, we considered that the absence of childspecific utilities contributed to uncertainty, and the evidence base for the recommendation could have been strengthened if child-specific utilities had been used. If only two of these factors were apparent or if there was some missing information, then we considered that this to be potentially the case.

\section{Results}

\subsection{Submissions to the PBAC}

There were 1889 PSDs available on the PBAC website [7]. Public summary document dates ranged from 2005 (when the PSDs were first posted publicly) to the time of data extraction (mid-February 2021), as outlined in Fig. 1. In total, there were 230 medicines/vaccines located in the sample frame that contained associated PSDs. At this stage of the search, if one PSD for the medicine was found, all associated PSDs for the medicine were retained. Of the 229 medicines included in the sample frame, 56 were duplicates, giving a total of 174 medicines with 947 associated PSDs. Of the 174 medicines, 82 medicines included PSDs with some reference to the population under consideration (persons under the age of 18 years, 269 associated PSDs) in any section of at least one of the associated PSDs. Of the 82 medicines referring to children, 29 medicines described the economic analysis as a cost-utility analysis (mentioning cost utility and/or QALYs). There were 62 PSDs with relevant information to the 29 medicines that were retained for data extraction. The number of PSDs in each year on the PBAC website increased over time (e.g. 82 PSDs in 2006; 192 PSDs in 2019).

Of the 62 PSDs that met the above criteria, 20 PSDs (ten medicines) described using a HRQOL instrument, of which four PSDs (two medicines) used child-specific HRQOL instruments. Eleven PSDs (eight medicines) used direct elicitation methods to generate child-specific utility values, and in 31 PSDs (16 medicines) the source of the utility values was not defined. Twenty-one PSDs (nine medicines) referred to vaccines. The perspective in all but one PSD was assumed to be from that of the healthcare system, given that the submissions were to the PBAC. Only one submission (meningococcal, November 2019) also included a societal perspective in some of its analyses.

\subsection{Child-Specific HRQOL Measure Used}

Four PSDs covering two medicines used child-specific HRQOL measures: Rotateq (rotavirus vaccine) and lisdexamfetamine (treatment of attention-deficit hyperactivity disorder). In both cases, the HRQOL measure used was the Health Utility Instrument Mark 2 (HUI2), a child-specific utility measure [16]. Information on age range, condition, submission date, source of utility value, use in decision making and outcome is presented in Table 1 . In the initial rotavirus vaccine submission, the economic evaluation was based on the use of parent proxy (the parent acted as a proxy in reporting HRQOL for their child) for the utility values. The PBAC did not recommend the initial submission on the basis of uncertain cost effectiveness at the requested price. The PBAC also expressed concerns about using parent proxy for the HUI2 values as the proxy measure for children may be difficult to interpret (Quote 1).

Quote 1: "The use of parents and/or care-givers as proxy raters of child utility [HUI2] may be appropriate 


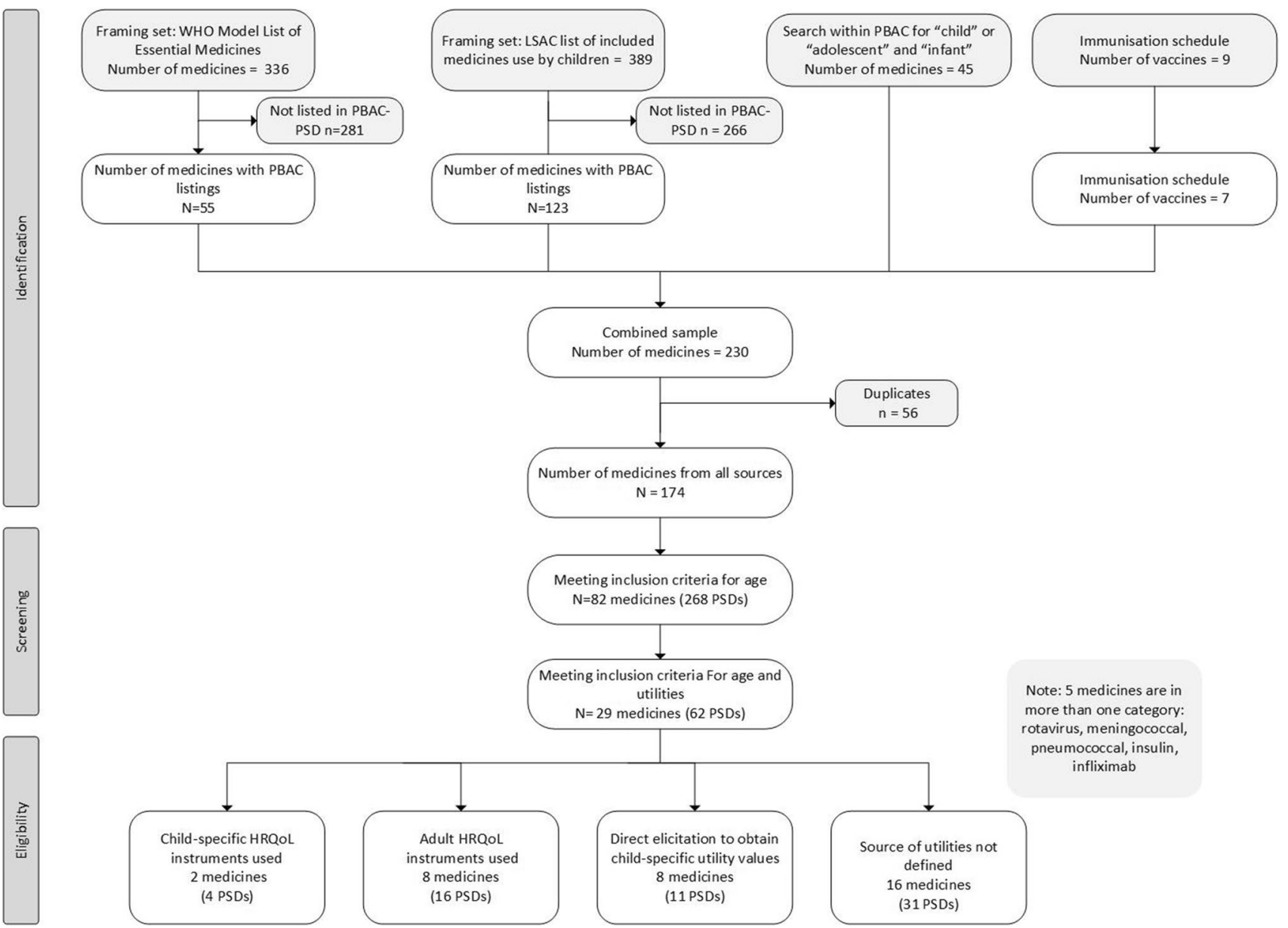

Fig. 1 Sampling frame and screening for the use of child-specific quality-of-life measures and utilities in (Pharmaceutical Benefits Advisory Committee [PBAC]) public summary documents (PSDs).
$H R Q o L$ health-related quality of life, LSAC Longitudinal Study of Australian Children, WHO World Health Organization

... While there may continue to be disagreement about whether it is appropriate to attempt to elicit QALY impacts for rotavirus, the method can be argued to be relatively conservative-particularly given that it uses a general practice population and applies the QALY weight only to the symptomatic days. Even if it is not appropriate to use a QALY metric in this case, it might be reasonably argued that this measure might be a reasonable proxy for the welfare impact (QOL) of rotavirus. It is unlikely that any more valid estimate will be available from an alternative method." (Rotateq submission, November 2006, page 3)

In the case of lisdexamfetamine, the initial submission (July 2013) was not recommended because of uncertain clinical effectiveness and unacceptable cost effectiveness. The PBAC did not accept the cost-utility analysis because the Committee did not consider there to be evidence of a clinical difference between the two medicines, and therefore resultant QALYs are reasonable. 


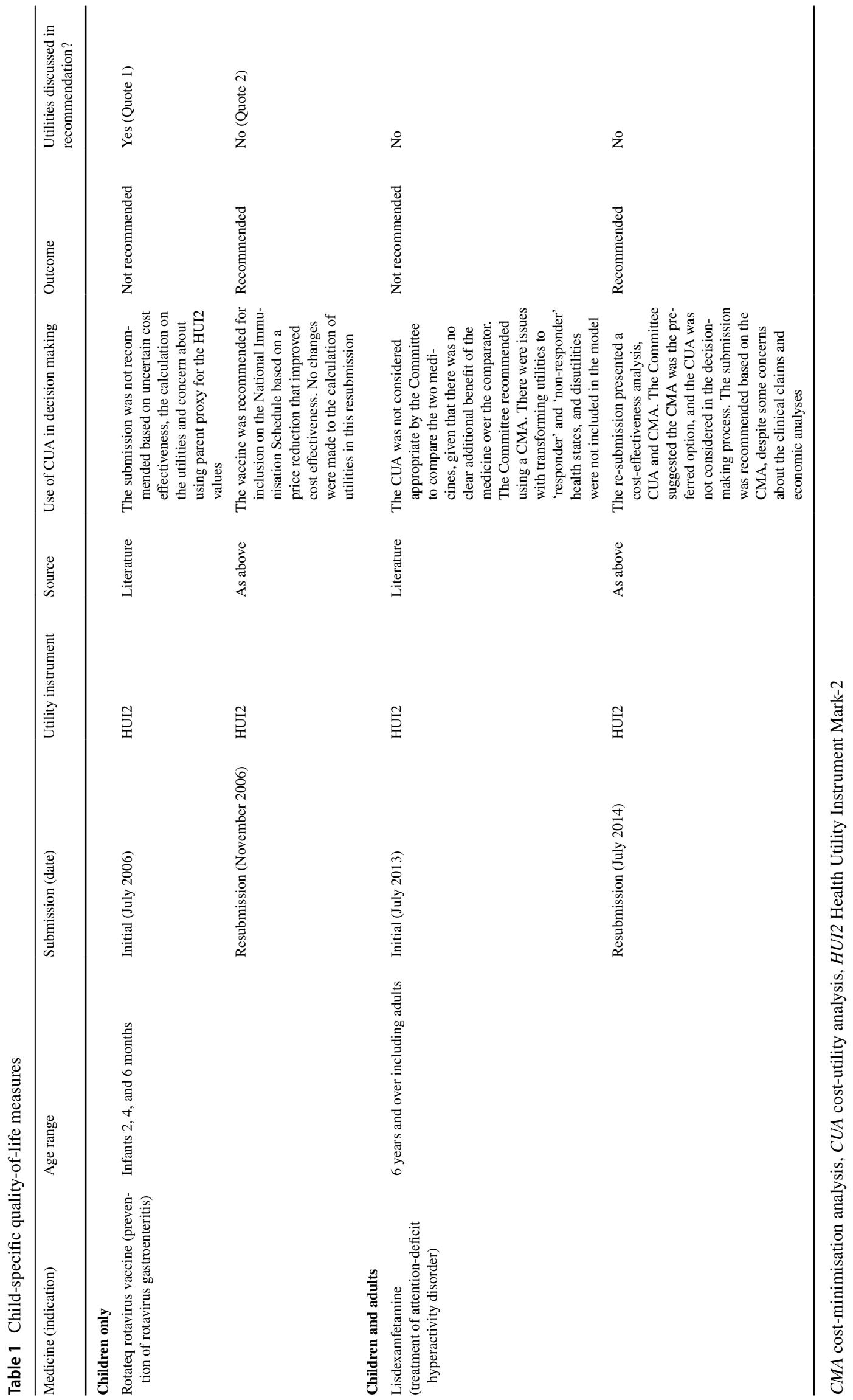


recommended the use of a cost-minimisation analysis instead. The PBAC noted that there were issues transforming utilities to 'responder' and 'non-responder' health states, suggesting that the Committee did not consider the cost-utility analysis was structured appropriately. In the resubmission 1 year later, cost-effectiveness, cost-utility and cost-minimisation analyses were presented, but the positive recommendation was based on the cost-minimisation analysis.

\subsection{Adult HRQOL Measure Used}

Of the 16 PSDs (eight medicines) where adult HRQOL measures were used, 15 PSDs reported the use of measures that were valued using preference weights for adult HRQOL: 13 PSDs used the EuroQol 5-dimension (EQ-5D) [17], four used the Assessment of Quality of Life Questionnaire (AQoL) [18] and two used the Asthma Quality of Life Questionnaire Five Dimensions (AQL-5D) [19], as shown in Table 2 (multiple measures may have been used in each submission). In one PSD (miglustat, July 2010) the SF-36 was reported, but there was no further information available in the PSD to inform whether this was mapped to the SF-6D to obtain preference weights.

There were four PSDs (two medicines) where adult measures of HRQOL were used for a population of children only (Table 2a). For the influenza quadrivalent vaccine (July 2019), the submission was specific to children aged 6 months to 5 years, but the adult EQ-5D-5L was used to estimate utilities (which could be appropriate if the QALYs are being estimated over a lifetime time horizon, though in this model the time horizon was 1 year). The model was noted to be sensitive to the utility values and the vaccine was recommended for listing by the Committee based on likely cost effectiveness. There were three sapropterin dihydrochloride submissions (for the treatment of hyperphenylalaninemia due to phenylketonuria) specific to neonates and children. The earlier submission (November 2011), seeking section 100 listing (special listing for highly specialised drugs [20]), used EQ-5D utility values sourced from an independent study commissioned by the sponsor. This submission was not recommended based on high and uncertain cost effectiveness. The model was sensitive to the utility values, and the Committee noted that the adult EQ-5D was not suitable for children (Quote 3).

Quote 3: "Uncertainty is also associated with the utilities derived for the health states included in the model given that the EQ-5D instrument was not developed for use in children, and the utilities derived describe the health of the parents of the children in several instances, rather than the health state of the children." (sapropterin, November 2011, page 8)
There were two subsequent submissions for sapropterin in March and November of 2018 with a new economic analysis, in which the Committee stated that the adult utility values from the EQ-5D lacked face validity in use for children's HRQOL. The Committee also discussed that it was not appropriate to use the child-specific utilities for adults because of the higher impact on children (Quote 4). A recommendation on the March submission was deferred, and a recommendation was made in the November submission to recommend the medicine with age and restrictions (must be commenced before the age of 18 years and allowed to continue thereafter), following a price reduction.

Quote 4: "The use of the same utilities for both adults and children was not clinically plausible. For example, the utility value of [retracted] (for the abandoned Phe-restricted diet, i.e. uncontrolled phenylketonuria, health state) was based explicitly on a child health state. The PBAC considered that it is highly likely that potential health impacts of uncontrolled phenylketonuria are more severe in infants and young children than in adults" (sapropterin, March 2018 Doc, page 22).

In the 12 PSDs (seven medicines) where adult HRQOL measures were used for both adults and children, the use of adult measures for children was not discussed as an issue in the PSDs. In the submission for miglustat (July 2010), it was specifically mentioned that the paediatric population was not included in the economic analysis.

\subsection{Direct Elicitation}

Of the 11 PSDs (eight medicines) that used direct elicitation methods, ten used time trade-off, standard gamble was used in two PSDs, discrete choice experiment, willingness to pay and a vertical rating scale were each used in one PSD (multiple techniques may be used in each submission; information on how the direct elicitation was conducted was rare). In two PSDs, EQ-5D scores were also collected, as shown in Table 3a where the population was children only and Table $3 \mathrm{~b}$ where the population was children and adults.

In two of the four PSDs where the population being considered for PBS listing was children only, concerns were raised about the appropriateness of the utility values. For instance, in the reference quoted for utilities in the pneumococcal polysaccharide conjugate vaccine submission (November 2010), parents were asked to trade off their own life to prevent repeated ear infections in their children (ear infections preventable through the vaccine [21]). For the Rotarix rotavirus vaccine (July 2006), which used standard gamble and discrete choice experiments, the Committee concluded that there was framing bias due to the anchor point used for the worst health state. Utilities 
values used in the diphtheria, tetanus, acellular pertussis vaccine submission (November 2014) were noted by the PBAC as being non-conservative; however, the model remained robust under all tested scenario analyses. For the PSD for leuprorelin (November 2014), a time tradeoff study was conducted where vignettes were retrospective, covering puberty and post-puberty aspects of the condition.

Where direct elicitation was used to inform utility values for medicines indicated for both adults and children, the Committee specifically commented on concerns regarding the use of time trade-off when making decisions about children (atomoxetine, for the treatment of attentiondeficit hyperactivity disorder, July 2006) as illustrated in Quote 5. The time trade-off methodology used was deemed appropriate by the PBAC for leuprorelin (November 2014), but not for tobramycin (March 2013), where the elicitation questions focussed mainly on the mode of administration. In the July 2015 submission for insulin glargine, the submission was for adults only, but the Committee was concerned that children may also use the subsidised medicine. In the consideration of etanercept, July 2008, evidence was reported that there were no differences in HRQOL between the two groups, and children's utilities were not explicitly mentioned.

Quote 5: "The PBAC noted that a key concern with the previous submission, the application of the TTO methodology to elicit utilities remained. The Economics Sub-Committee advised the key issue with the elicitation of utilities is that a time trade off (TTO) approach in which a subject is asked to trade off someone else's life is not comparable with a standard time trade off approach because it does not have the same basis in utility. A QALY weight is a person's individual preference ranking about health states for themselves. Even if an adult is asked to imagine that she was a child, it is the adult who then has to answer how much she wants to trade-off the child's life whereas in standard TTO the adult would be asked how much of her own life she would trade off. Implicitly the utility function which has the adult's survival, and the adult's quality of life is then taken as the child's utility function." (atomoxetine, July 2006, page 4)

\subsection{Source of Utilities not Reported or Discussed in PSDs}

There were 31 PSDs (16 medicines) where the utility values were not reported or discussed, as shown in Table 4. Of these, 17 PSDs (eight medicines) were specific to children (first section of Table 4a). There were four PSDs relating to Gardasil, and three to Cervarix, both of which are vaccines against the human papilloma virus. In the initial submission for Gardasil (November 2006), which was for girls aged 12-13 years and with a catch-up programme, utilities appeared to be related to cancer health states and were deemed by the PBAC to have been overestimated. The submission of extension to the program to boys (March 2011) was initially not recommended because of high and uncertain cost effectiveness but was subsequently recommended in November 2011 based on acceptable cost effectiveness compared with vaccination for girls and following a price reduction. The final submission was to reduce the schedule from three to two doses (July 2017). For the three Cervarix documents, cost-utility analyses were conducted alongside a cost-minimisation analysis, but the source of the utility values was not reported or discussed in the documents. The July 2007 submission was not recommended because of concerns about clinical differences between Cervarix and Gardasil, but the resubmission that included a price reduction (Cervarix, November 2007) was recommended. In November 2015, dosage was dropped from three to two doses, and in the July 2017 submission, boys were added to the schedule. It is important to note that the human papilloma virus vaccines are administered to children, but the health benefits accrue to adults; thus, it is less clear cut whether child-specific utilities are as relevant in this case.

Apart from the human papilloma virus vaccines, there were a further ten PSDs where the population was children only. For the July 2007 submission for infliximab (treatment for ulcerative colitis), utility values were derived from a small survey of clinicians in Australia and were perceived by the PBAC as lacking face validity. It was not possible to determine from the PSD whether clinicians were asked to indicate how relevant health states would be described on a standard measure of HRQOL accompanied by preferences or asked to directly estimate a raw utility score; thus, we were not able to allocate this PSD to the direct elicitation section.

In the measles, mumps, rubella and varicella vaccine submission (November 2007), the submission was recommended based on clinical need, despite concerns with the cost-effectiveness basis for pricing of the vaccine. Although the recommendation for the meningococcal vaccine submission (July 2018 with August 2018 addendum) was made on a cost-minimisation basis, QALYs were recommended to be used to indirectly quantify a clinically important difference between the two vaccines, where the cost per QALY gained would be less than $\$ 15,000$ (the PBAC noted that this recommendation was yet to be implemented). The methylphenidate hydrochloride submission (March 2006) was not recommended based on uncertain clinical benefit and cost effectiveness because the PBAC had concerns that the clinical and other benefits of an extended-release formulation and once-a-day administration had not been demonstrated 


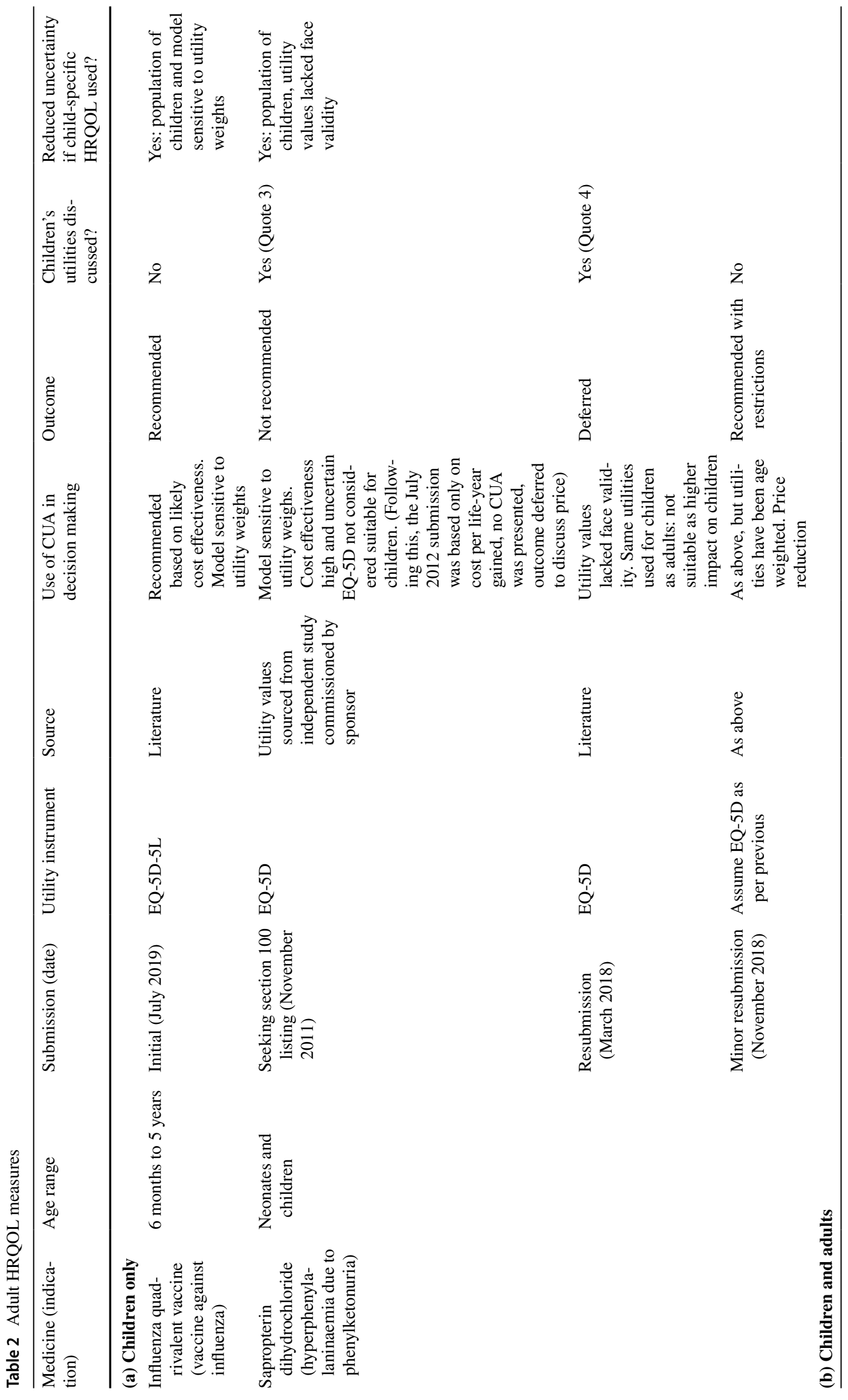




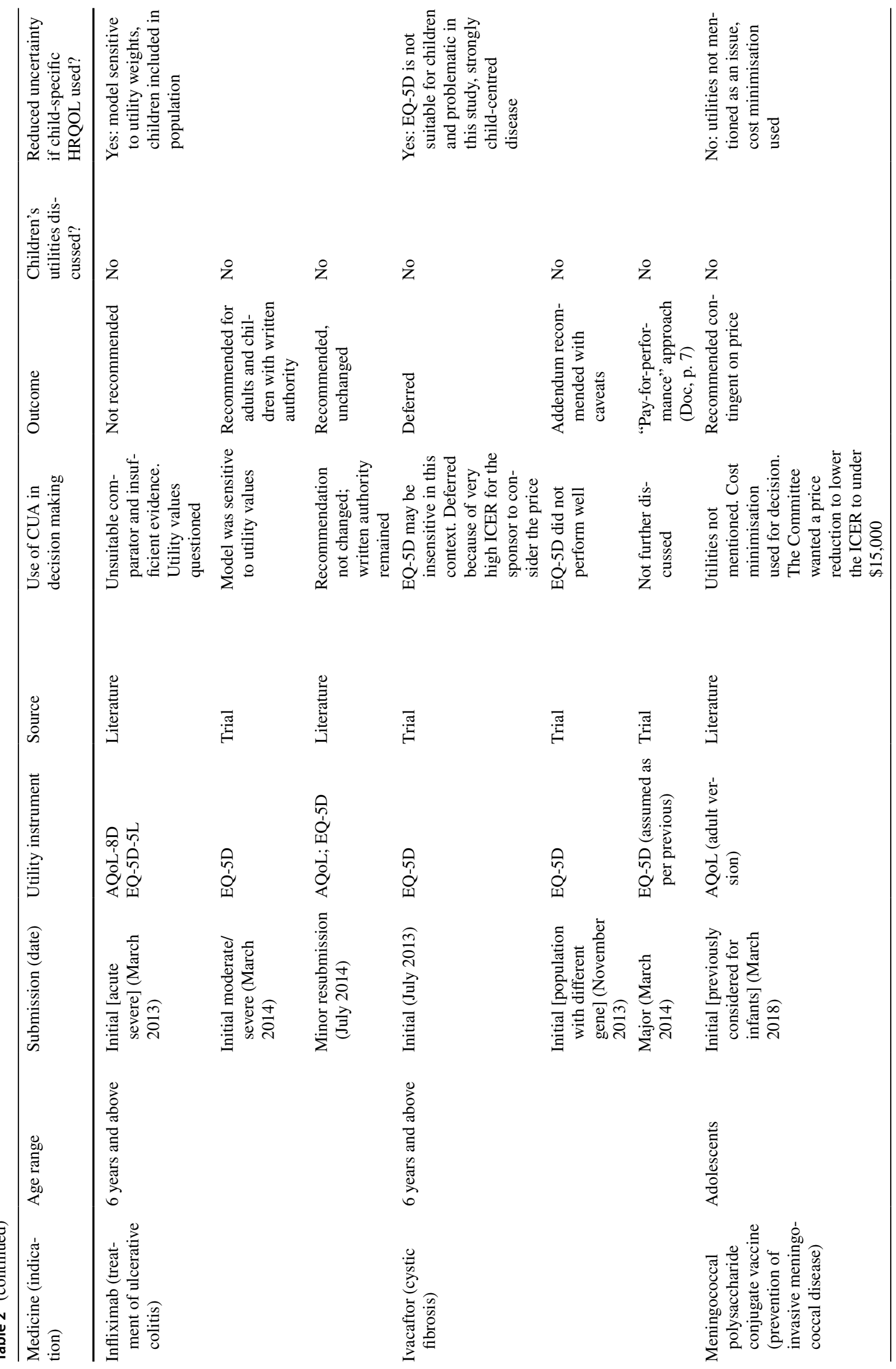




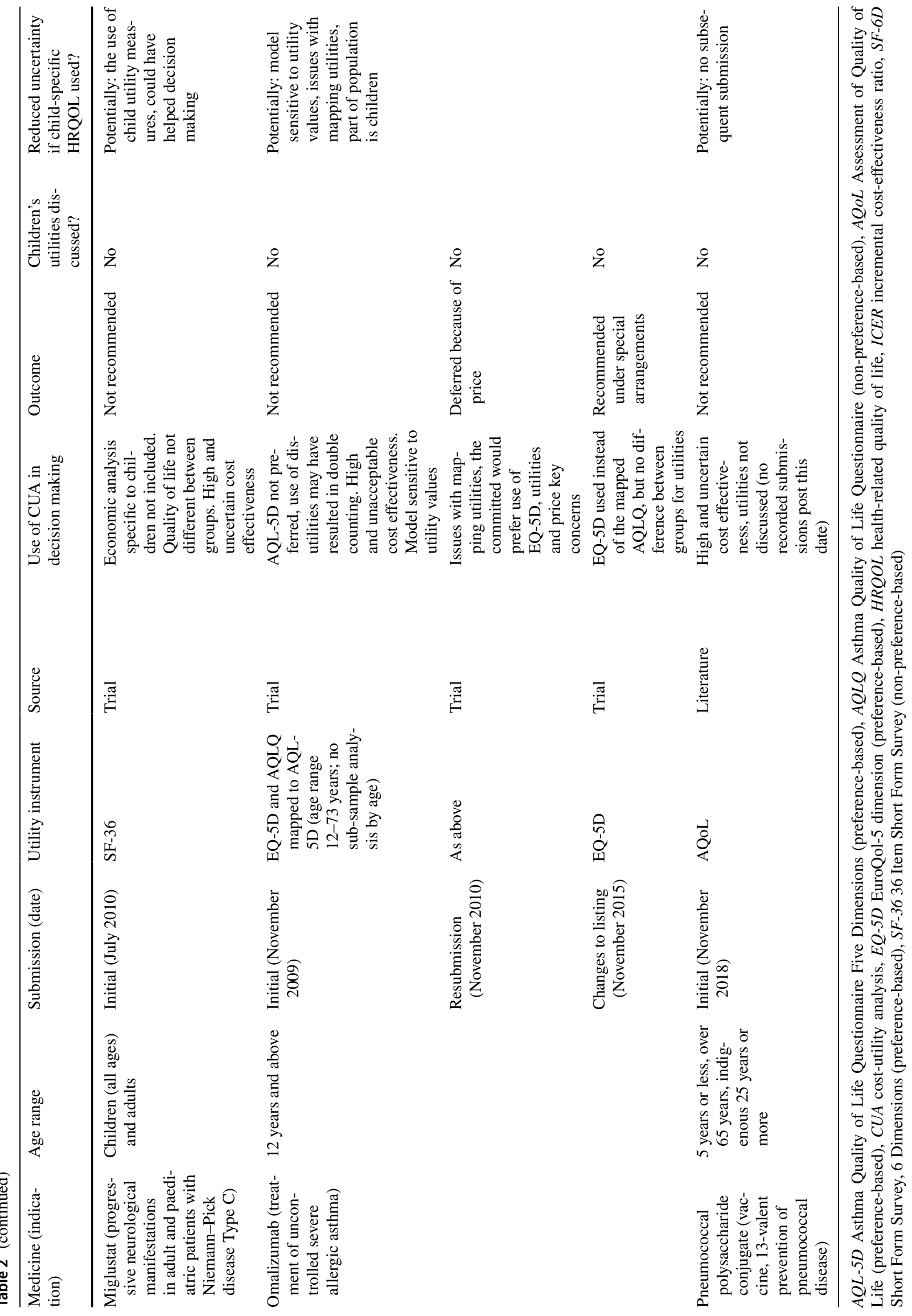




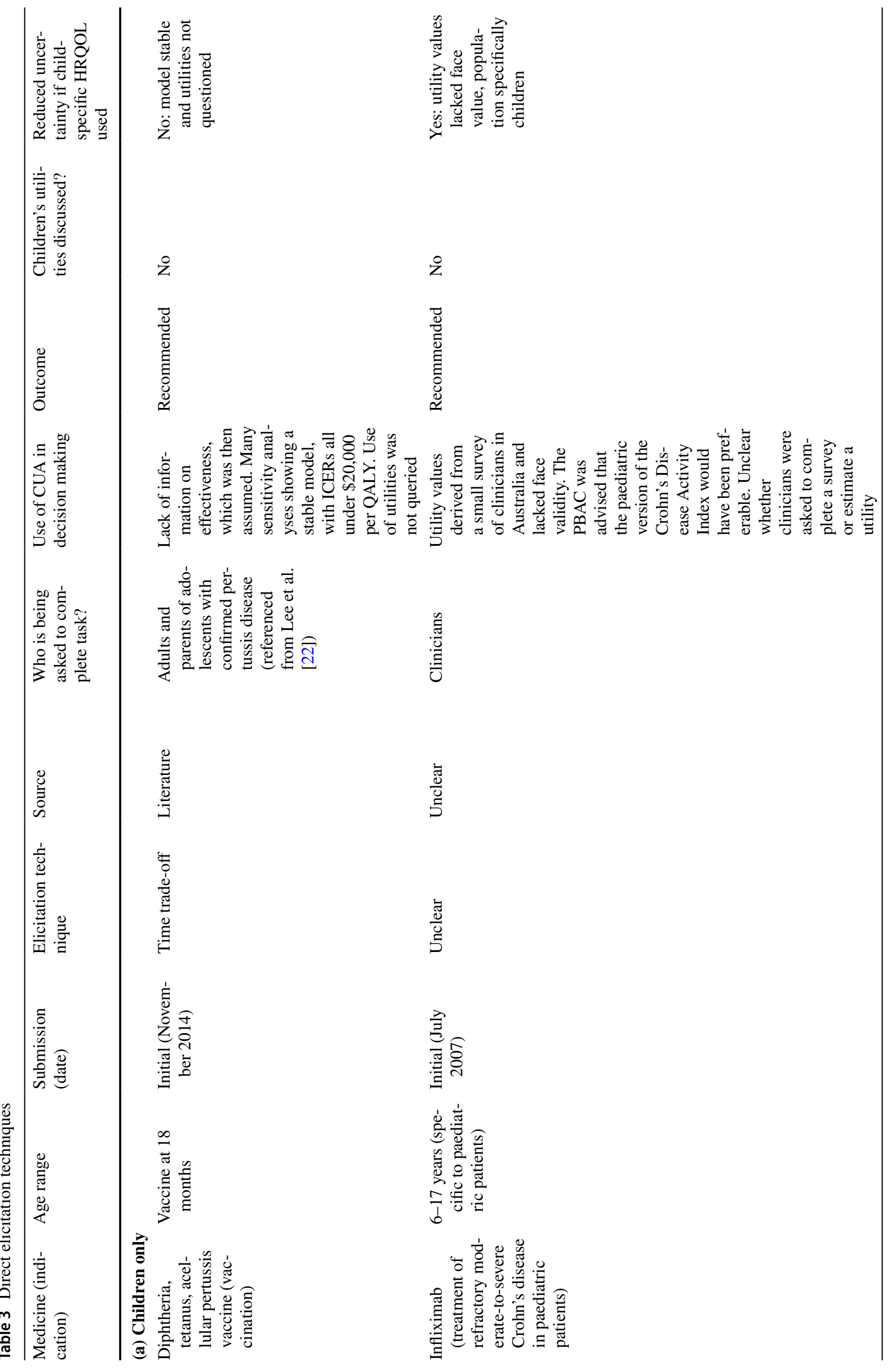




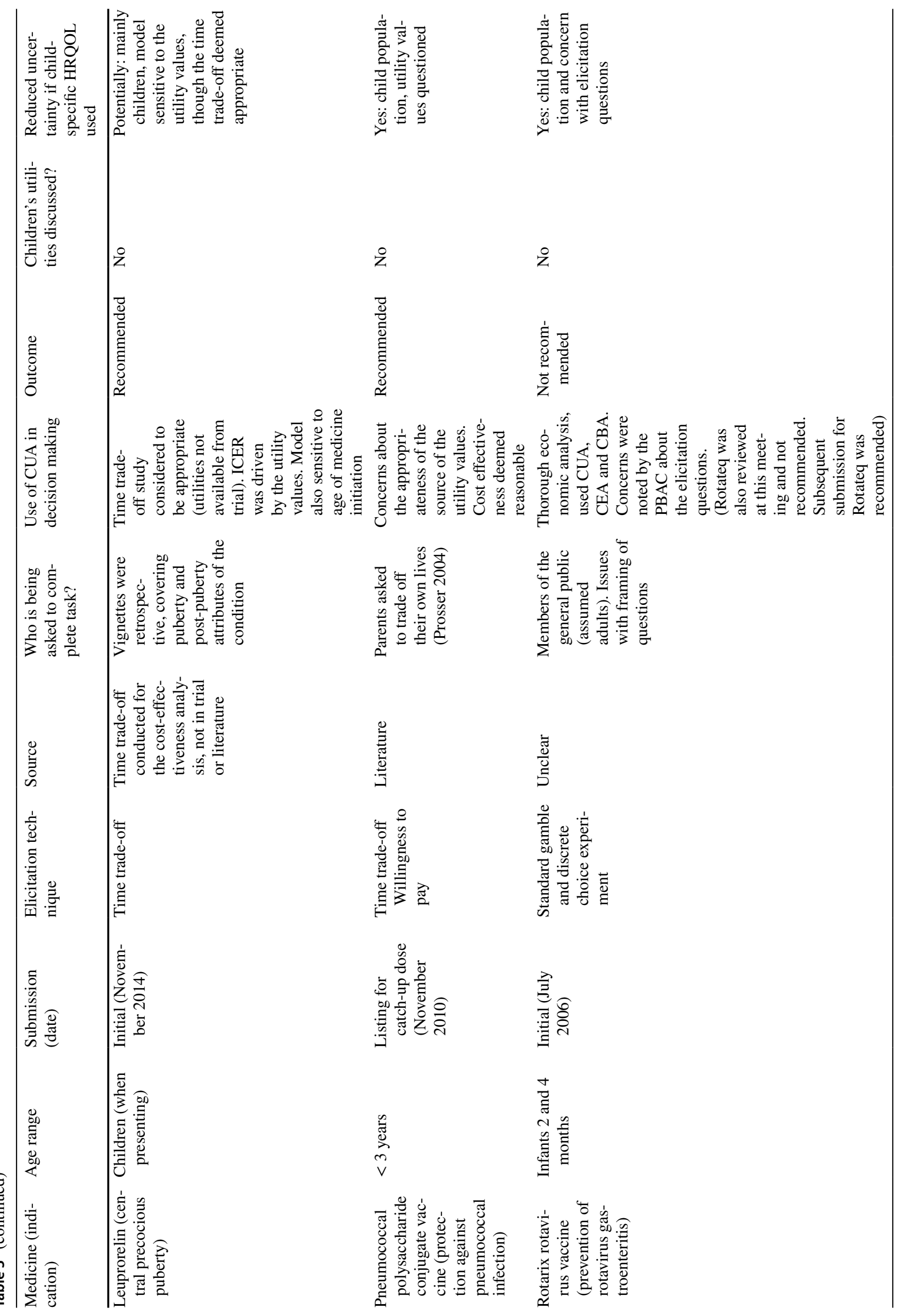




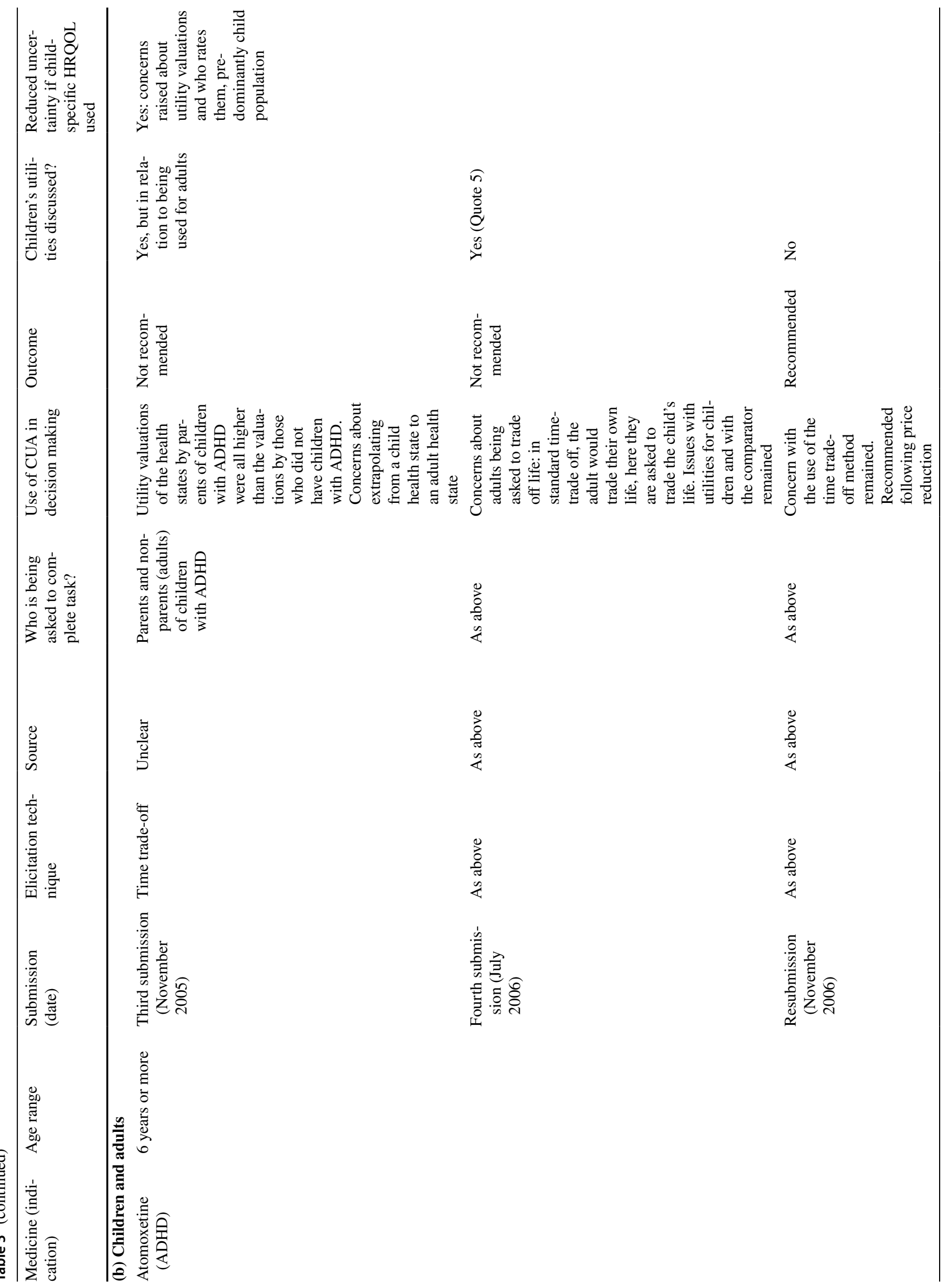




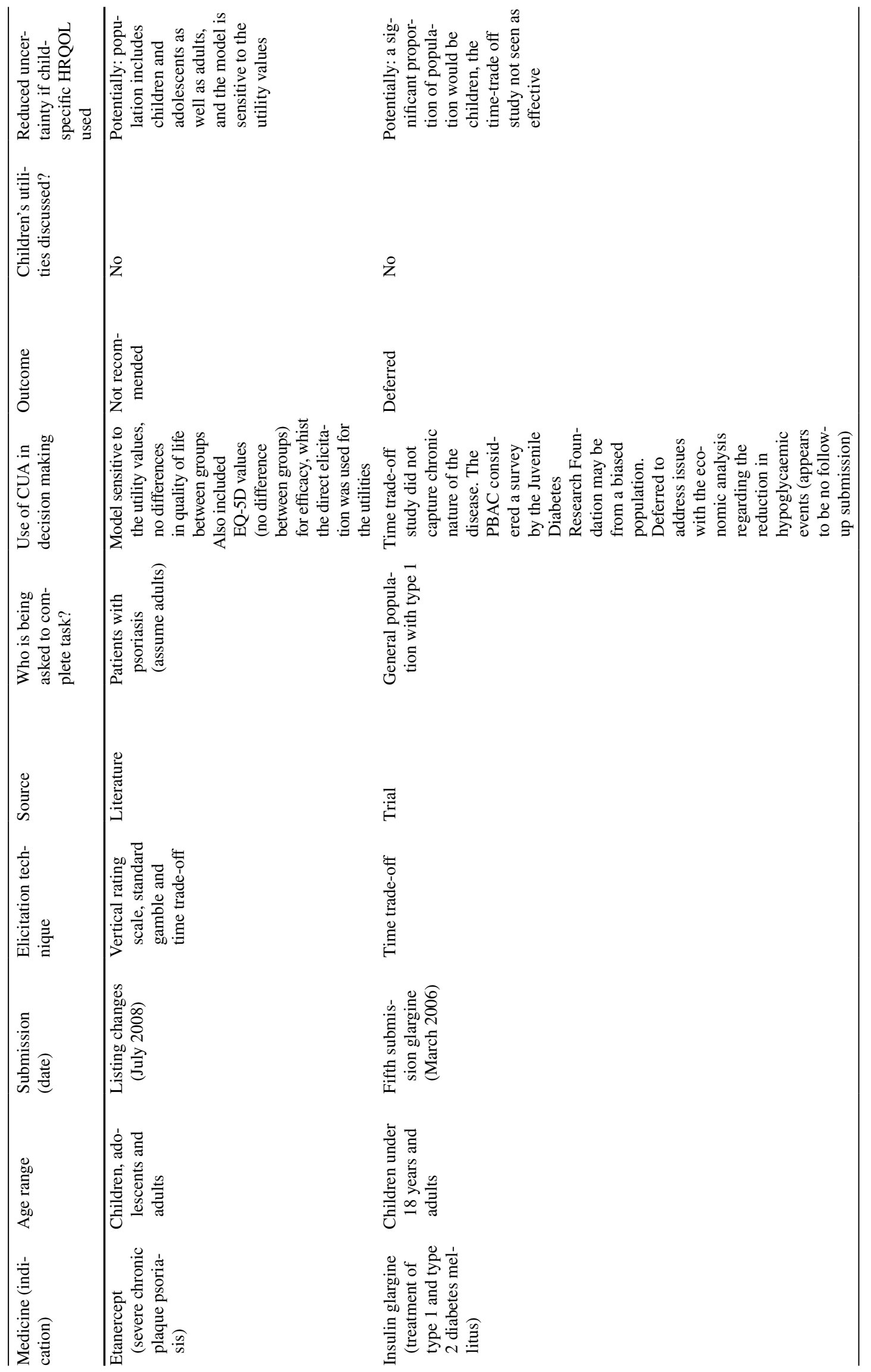




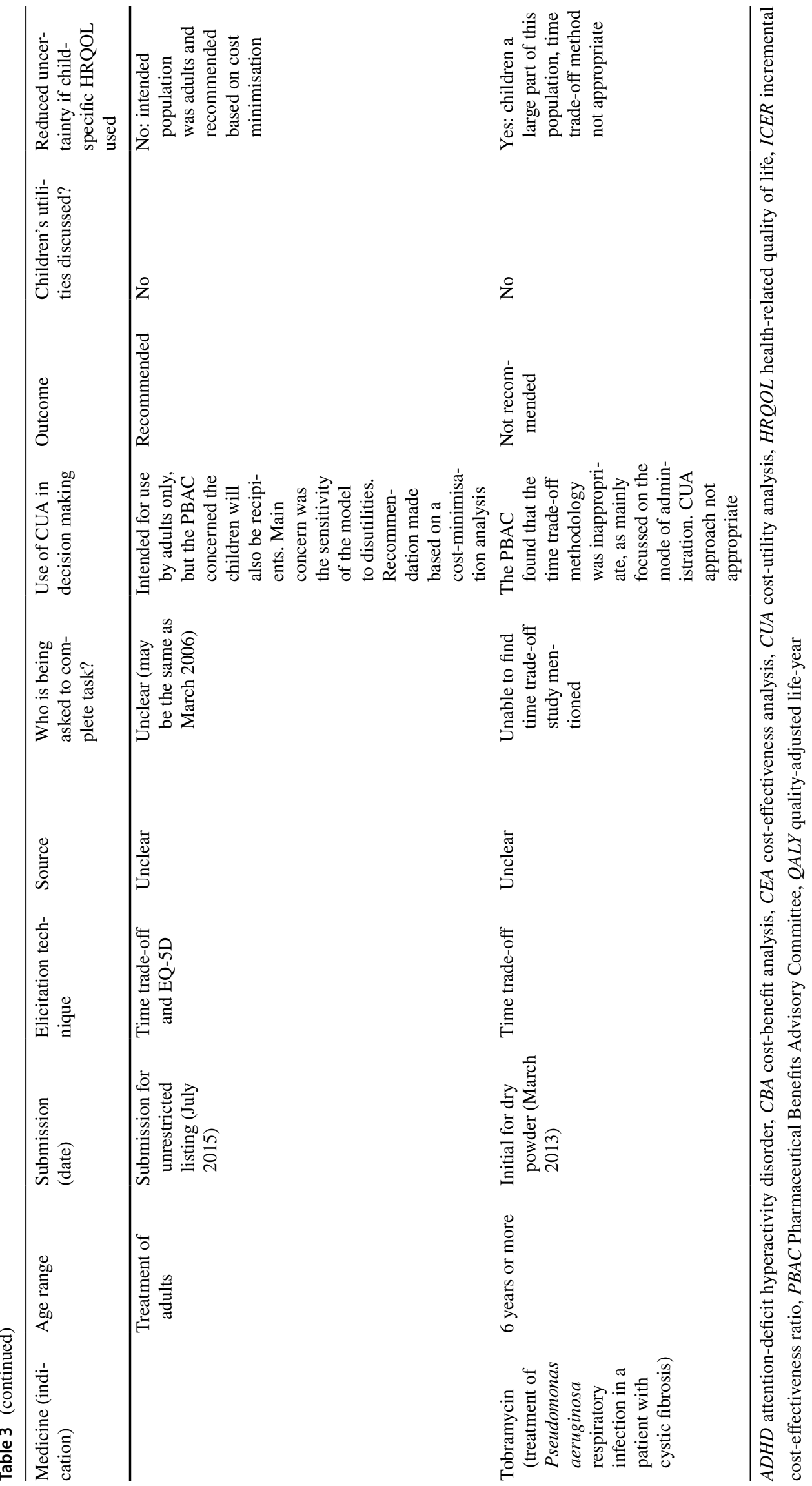




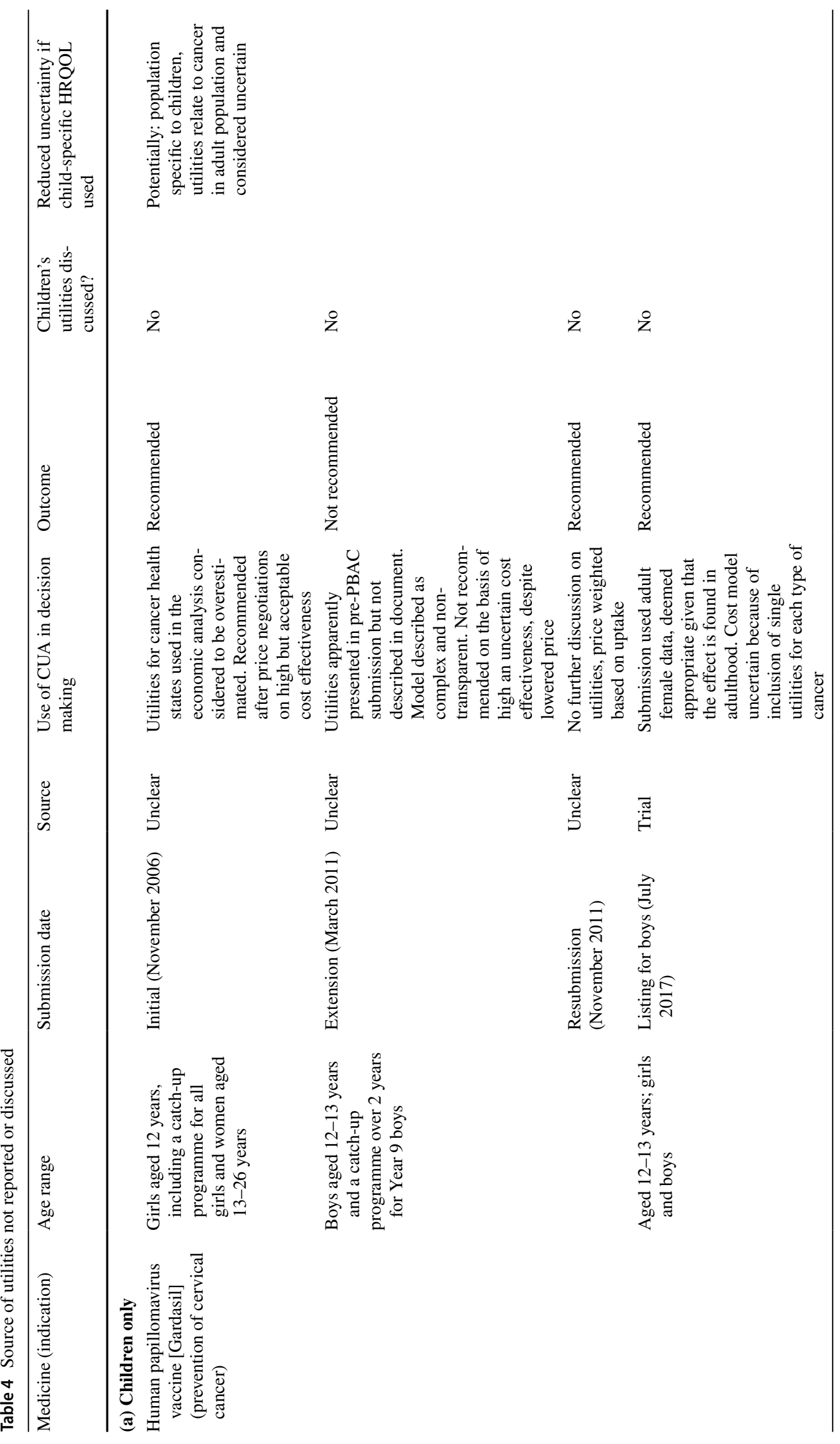




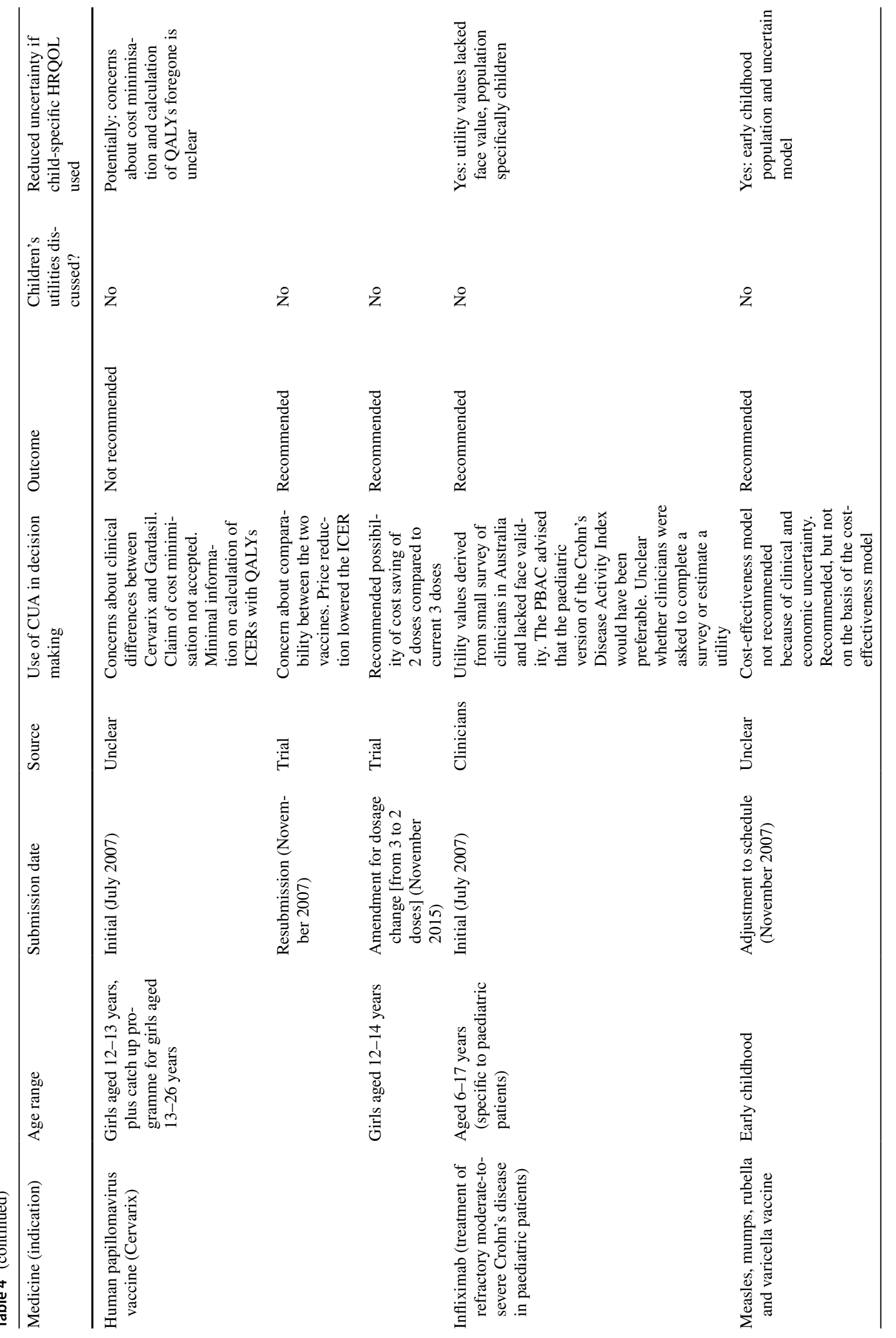




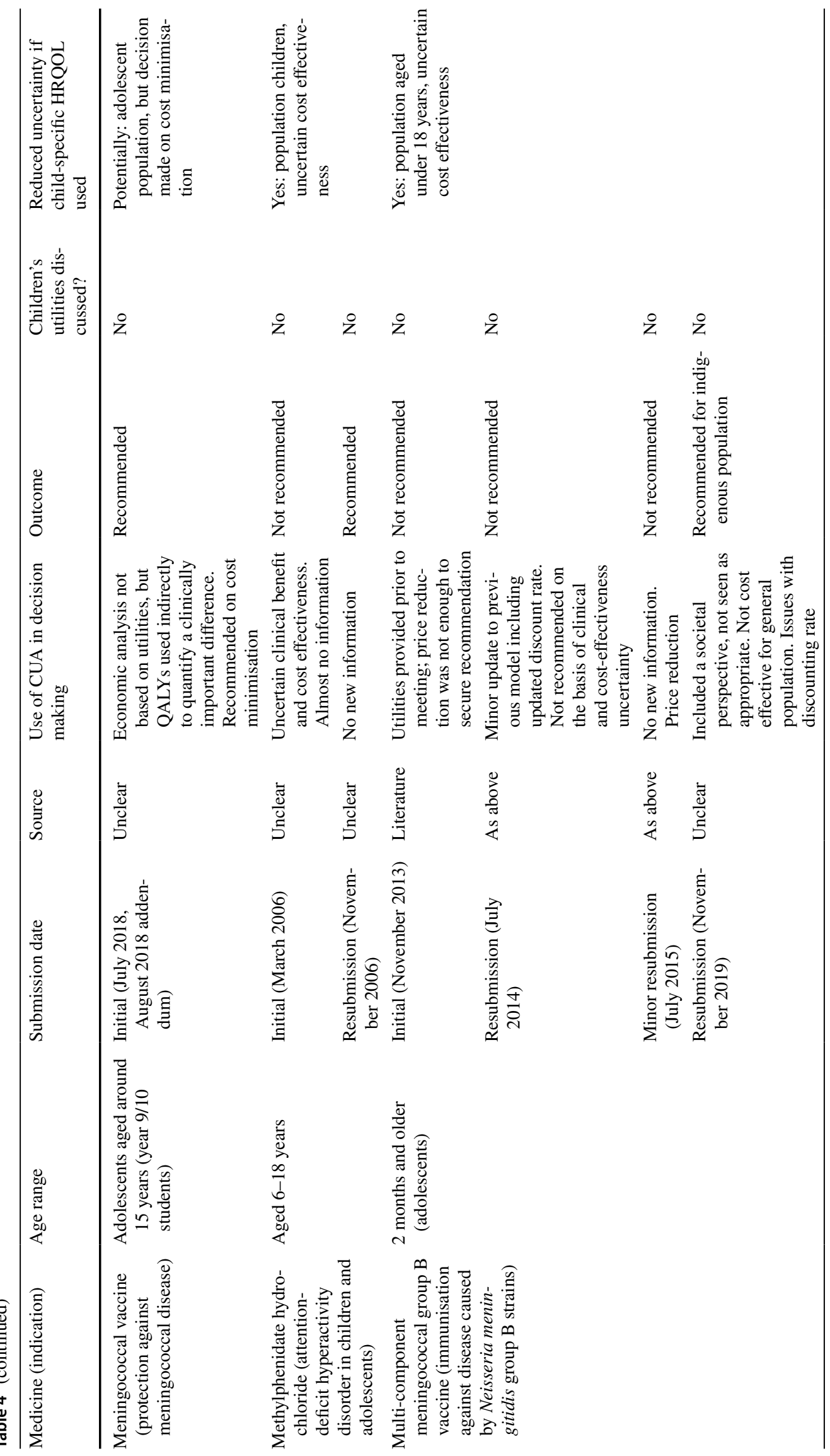




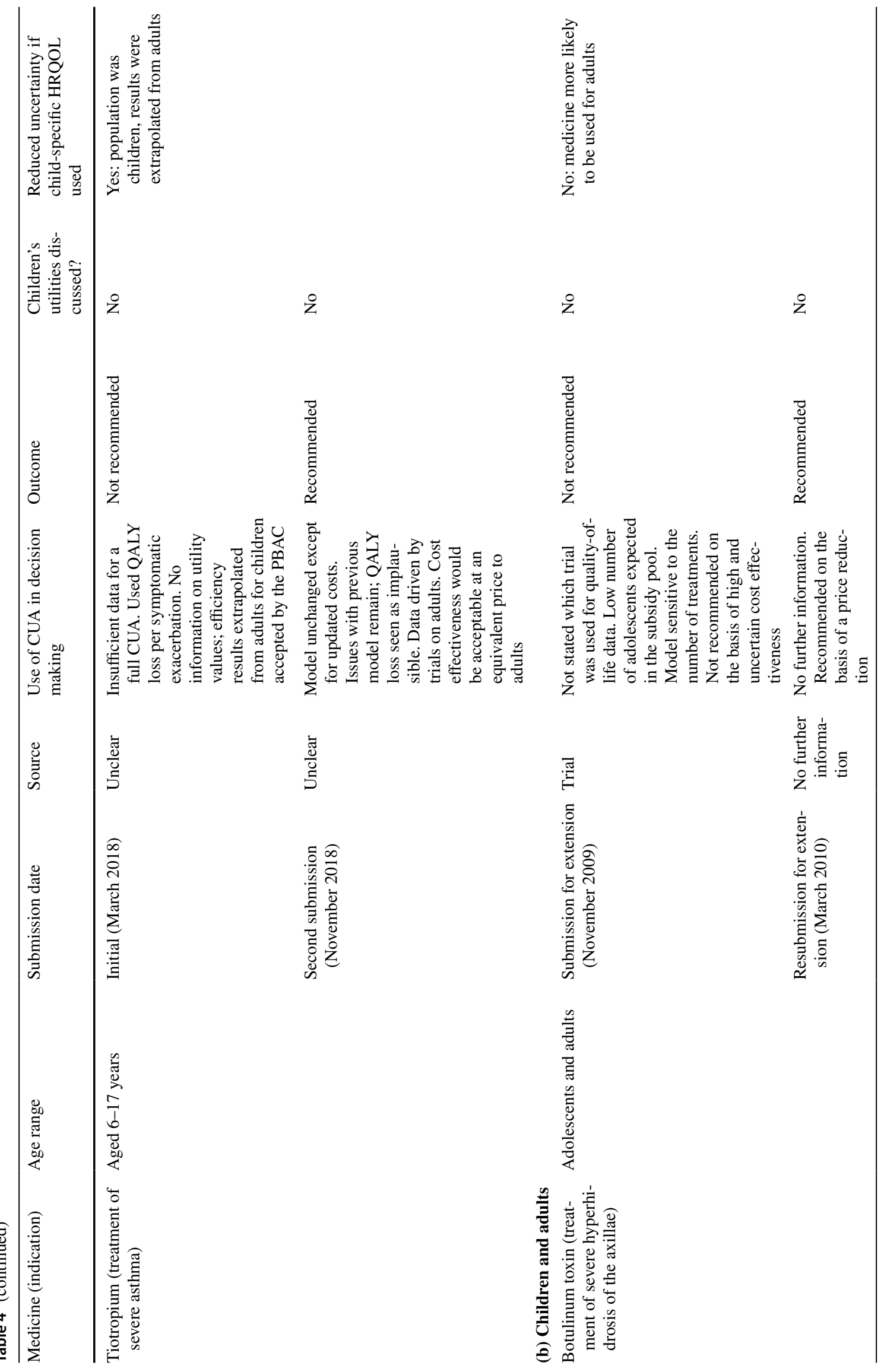




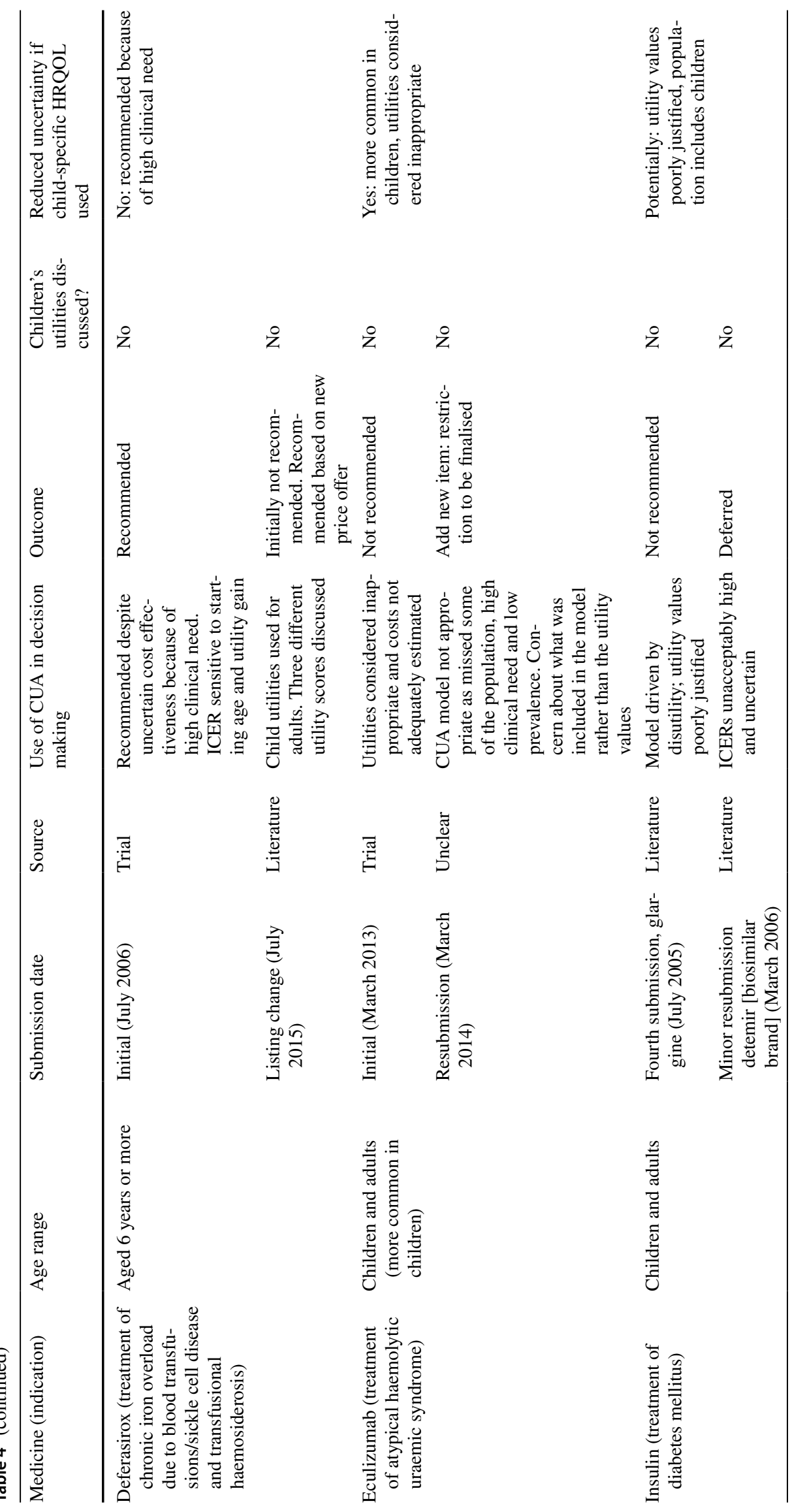




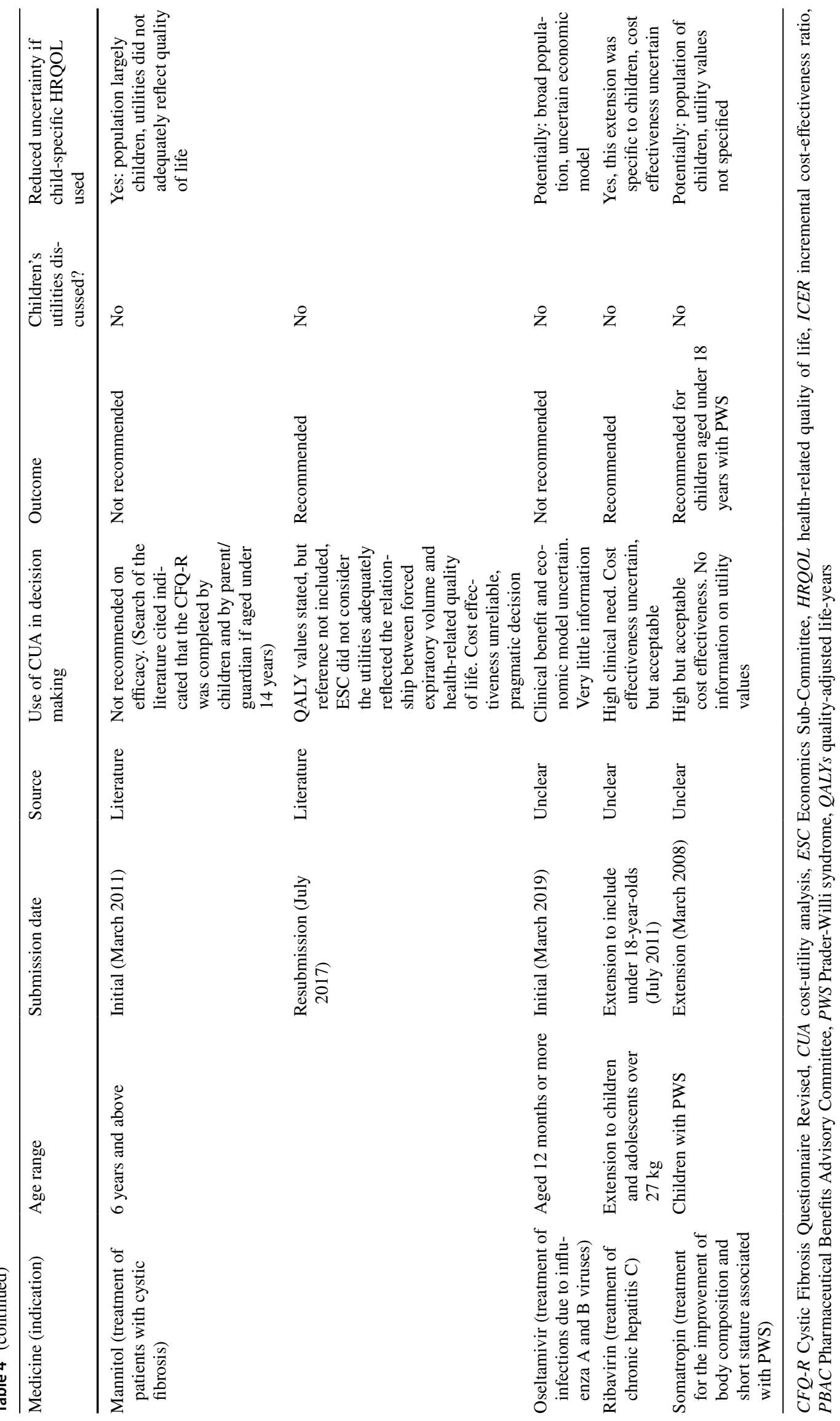


Table 5 Summary table of whether there would have been reduced uncertainty if child-specific health-related quality-of-life measures had been used $(n=34)$

\begin{tabular}{|c|c|c|c|c|c|c|}
\hline & \multicolumn{2}{|c|}{ Reduced uncertainty $(n=17,50 \%)$} & \multicolumn{2}{|c|}{$\begin{array}{l}\text { Potentially reduced uncertainty }(n= \\
12,35.3 \%)\end{array}$} & \multicolumn{2}{|c|}{$\begin{array}{l}\text { Not reduced uncertainty } \\
(n=5,14.7 \%)\end{array}$} \\
\hline & No. & Medicine & No. & Medicine & No. & Medicine \\
\hline Table 2 & 4 & $\begin{array}{l}\text { Influenza quadrivalent vaccine } \\
\text { Sapropterin dihydrochloride } \\
\text { Infliximab } \\
\text { Vacaftor }\end{array}$ & 3 & $\begin{array}{l}\text { Miglustat } \\
\text { Omalizumab } \\
\text { Pneumococcal polysaccharide } \\
\text { conjugate }\end{array}$ & 1 & $\begin{array}{l}\text { Meningococcal } \\
\text { polysaccharide } \\
\text { conjugate } \\
\text { Vaccine }\end{array}$ \\
\hline Table 3 & 5 & $\begin{array}{l}\text { Infliximab } \\
\text { Pneumococcal polysaccharide conjugate vaccine } \\
\text { Rotarix } \\
\text { Atomoxetine } \\
\text { Tobramycin }\end{array}$ & 3 & $\begin{array}{l}\text { Leuprorelin } \\
\text { Etanercept } \\
\text { Insulin glargine }\end{array}$ & 2 & $\begin{array}{l}\text { Diphtheria, teta- } \\
\text { nus, pertussis } \\
\text { vaccine } \\
\text { Insulin glargine }\end{array}$ \\
\hline Table 4 & 8 & $\begin{array}{l}\text { Infliximab } \\
\text { Measles, mumps, rubella and varicella vaccine } \\
\text { Methylphenidate hydrochloride } \\
\text { Multi-component meningococcal group B vaccine } \\
\text { Tiotropium } \\
\text { Eculizumab } \\
\text { Mannitol } \\
\text { Ribavirin }\end{array}$ & 6 & $\begin{array}{l}\text { Gardasil } \\
\text { Cervarix } \\
\text { Meningococcal vaccine } \\
\text { Insulin (glargine, detemir) } \\
\text { Oseltamivir } \\
\text { Somatropin }\end{array}$ & 2 & $\begin{array}{l}\text { Botulinum toxin } \\
\text { Deferasirox }\end{array}$ \\
\hline
\end{tabular}

adequately in the trial, and because there were other concerns with the economic model. It was subsequently recommended in the November 2006 resubmission on the basis of ease of administration because it removed the need for a dose during school hours. The four multi-component meningococcal group B vaccine PSDs were not recommended for the general population, despite the subsequent submissions including a price reduction. In the final submission (November 2019), a societal perspective was included, which was not considered appropriate by the PBAC. The vaccine was subsequently recommended for indigenous populations only. The final medicine specific to children only was tiotropium. Both submissions used QALY loss per symptomatic exacerbation, and extrapolated QALYs from adults to children. The Committee accepted the extrapolation, but the QALY loss was considered to be implausible. The initial submission (March 2018) was not recommended, but the second submission (November 2018) was recommended after a price reduction.

Concern about using adult utilities for children was not raised in the 13 PSDs (eight medicines) where the conditions and medicines were for both adults and children in this section. The Committee queried the use of child utilities for adults in the deferasirox July 2015 submission.

\subsection{Use of Child-Specific HRQOL Measures to Reduce Uncertainty}

Information from the final column of Tables 2, 3 and 4 has been summarised in Table 5. As per Fig. 1, there were 29 include medicines; however, two medicines were excluded as they already used child-specific HRQOL measures (as per Table 1), four medicines were included in two tables (rotavirus, meningococcal, pneumococcal, insulin). Infliximab was included in all three tables, and insulin glargine submissions were separately classified in Table 3, hence there are 34 medicines included in Table 5. Across all three tables, we estimated that if child-specific measures had been available and used, this would have reduced uncertainty for decision making in 17 medicines (50\%), and potentially reduced uncertainty in a further $12(35.3 \%)$. In five medicines (14.7\%), we estimated that using child-specific HRQOL measures would not have reduced uncertainty in decision making. We thus conclude that in $85.3 \%$ of cases, the use of child-specific HRQOL measures may reduce uncertainty for decision makers.

\section{Discussion}

In this study, we aimed to investigate the use of child-specific HRQOL measures and child-specific utility values in recommendations made by the Australian PBAC. Using a comprehensive sample frame, we found that out of the 1889 PSDs, 62 PSDs pertained to children and contained cost-utility analyses (or mentioned QALYs or utility values). Of these 62 recommendations involving a cost-utility analysis of childhood medicines (29 medicines), only four PSDs (two medicines) used a child-specific HRQOL measure that generated the child-specific utility values that were used in cost-utility analyses. In both cases, the utility value was derived from the Health Utility Index Mark-2 (HUI2). 
The Committee expressed concern about the calculation of the utilities and the use of the parent-proxy for the HUI2 in the Rotateq (rotavirus vaccine) submissions. For lisdexamfetamine (treatment of ADHD), the Committee was concerned about utility transformation, but recommended a cost-minimisation analysis instead of a cost-utility analysis as there was no evidence of a clear additional benefit between the medicine and comparator. Of note, there are many preference-based measures that have been developed for child and adolescent populations (e.g. AHUM, AQoL6D, CHU9D, EQ-5D-Y, HUI3, QWB, 16D and 17D; only the HUI2 appears to have been used in in the PBAC submissions [4]); however, submissions to the PBAC are dependent on appropriate preference-based measures being used in the clinical trials that form the basis of these submissions.

The use of adult measures of HRQOL to inform a costutility analysis of interventions for children was found in 16 PSDs. The Committee commented on the use of adult HRQOL measures for use in children in only one case (sapropterin, March 2018) by noting that the EQ-5D was not developed for use in children. Other methods to determine HRQOL values were through direct elicitation methods, the most common of which was time trade-off. In these cases, the PBAC often raised methodological concerns. Issues raised by the PBAC (as reported in the PSDs) in relation to direct elicitation of child utilities included adults trading off children's lives (atomoxetine, July 2006), and adults trading off their own lives (pneumococcal polysaccharide conjugate vaccine, November 2010). There is a risk with direct elicitation that studies will focus directly on the area that the treatment improved, as illustrated by the case of tobramycin (treatment of cystic fibrosis, March 2013) where the questions referred to the mode of administration. The PBAC also noted that the wording used in vignettes may introduce bias, such as in the case of leruprorelin (treatment of central precocious puberty, November 2014) with the use of the term 'stunted growth'.

The PBAC considers the comparative clinical benefit and value for money of new medicines compared with current treatments, and it is important to consider how the lack of child-specific HRQOL or utilities as evidence affects decision making by the Committee, and similar bodies. The utilities are a key input to the economic models that inform value for money, and uncertainty around utility values directly impacts the incremental cost-effectiveness ratio. Child-specific HRQOL instruments have been designed around the domains and descriptors of quality of life that are relevant to children. When used, these instruments should provide greater clarity to decision makers about how the interventions improve patient well-being in the treated population, compared to adult measures.

One of the main findings in this study was that a lack of child-specific HRQOL measures increased uncertainty in decision making, when medicines were used by children. Of the 33 medicines where child-specific HRQOL measures were not used, we consider that in 16 medicines (48\%) uncertainty would have been reduced if child-specific HRQOL measures were used, and in 12 medicines (36\%) uncertainty would potentially have been reduced (total of 29 medicines, 27 did not use child-specific medicines, six were considered in more than one table, giving 33 medicines for this analysis). In only five medicines (15\%) was the use of child-specific HRQOL measures unlikely to have reduced uncertainty according to our assumptions (based on whether a cost-utility analysis was used in the recommendation, the model was sensitive to utility values and children were an important part of the population under consideration). Thus, we can say that in $85 \%$ of cases, uncertainty would have or possibly would have been reduced.

In this review, we found that in almost every instance where patient HRQOL was relied on for a paediatric population, the PBAC did not have child-specific quality-of-life information or utility values to inform the recommendation. The PBAC makes deliberations on whether to recommend or reject a medicine based on the information that it has available, and any area where information is missing will be a source of uncertainty. Appropriate utility values are one of the sources for decision making. Because the PBAC is deciding to reject or recommend at a specific requested price and with specific models and assumptions, if the information is not as good as it could be then the evaluation process is less than optimal, and could result in paying too much for a medicine or rejecting it when it should be accepted (delaying access).

\subsection{Limitations}

The sample frame of medicines used by children in this study was informed from multiple sources, and PSDs were systematically searched for eligibility for the study. Despite this rigorous method, the possibility that relevant submissions were overlooked remains. By their nature as summary documents, the PSDs lack complete detail, and there are redactions of key information because of commercial sensitivity, mainly pertaining to costs, QALYs, and incremental cost-effectiveness ratios. Where the utility was not mentioned in the PSD, it was hard to identify the details of the utility values used. We relied on the PBAC public summary documents to reflect decision makers views, and note that there are other documents, including the evaluation commentaries from PBAC's external evaluators and the advice from the Economics Sub-Committee may contain more information than is included in the PSDs. These documents and the full submissions from the sponsors are not in the public domain, but remain a potential source for future research. Other methods to 
understand a decision maker's views may be to conduct interviews or surveys. It is also pertinent to note that the amount of detail presented in the PSDs evolved over time. Future directions for research may include strengthening the evidence regarding the validity of existing child HRQOL measures, further valuation of child HRQOL measures including country-specific value sets, advancing the measurement of HRQOL in younger children, determining at what age an adult instrument may be suitable for adolescents, clinical trials, sponsor guideline requirements and health technology assessment evaluation processes.

\section{Conclusions}

Internationally, there is growing emphasis on measuring and valuing HRQOL in ways that are valid, relevant and meaningful for decision makers to assess the impact of medicines and interventions. This review aimed to investigate the use of child-specific HRQOL measures in decision making by the Australian PBAC and found that use of these measures or utilities is relatively uncommon. In $85 \%$ of medicines that did not use child-specific utilities, we estimated that uncertainty may have been reduced if child-specific utility measures had been used. Our review suggests that current evidence being submitted on the measurement and valuation of child HRQOL for use in PBAC recommendations is limited and contributes to uncertainty about value for money: there is evidence of inappropriate measures and weights being used, cases in which there is a gap in knowledge about the quality-of-life impacts on children and other gaps in evidence. Better methods for estimating child-specific utility gains (and guidance to users about where these should be applied) may improve the evidence base for decision making for interventions for children in Australia and thus help to inform the PBAC's consideration of value for money. To inform decision making, it would be preferable for trials of interventions to treat healthcare conditions in children to collect quality-of-life information with a child-specific utility instrument. Appropriate methods to inform resource allocation are needed to determine how the community trades off different aspects of quality of life and survival for children.

Supplementary Information The online version contains supplementary material available at https://doi.org/10.1007/s40273-021-01107-5.

Acknowledgements The authors thank Jo Watson and Andrew Mitchell for their careful review of a draft, and advice on matters of fact and language in relation to the description of PBAC deliberations.

\section{Declarations}

Funding This study was funded through the Medical Future Research Fund (Grant number: APP1200816).
Conflict of interest Cate Bailey, Kim Dalziel, Paula Cronin, Nancy Devlin and Rosalie Viney declare that they have no conflict of interest. Rosalie Viney was a member of the PBAC and Chair of its Economics Sub-Committee for much of the period covered by this review. Paula Cronin has been an evaluator for PBAC submissions. Kim Dalziel has been an evaluator for the PBAC and has acted as a guest discussant on the Economics Sub-Committee. Note: The Economics Sub-Committee comprises clinical and economics experts who review the submissions and the commentaries and provide advice to the PBAC. This includes reviewing and commenting on the data, methods and assumptions used in submissions and whether they are valid, and possible implications for PBAC's considerations.

Ethics approval Not applicable.

Consent to participate Not applicable.

Consent for publication Not applicable.

Availability of data and material All data are publicly accessible through the PBAC website.

Code availability Not applicable.

Author contributions Conceptualisation: $\mathrm{CB}, \mathrm{KD}, \mathrm{ND}, \mathrm{RV}$; formal analysis and investigation $\mathrm{CB}, \mathrm{KD}, \mathrm{PC}, \mathrm{ND}, \mathrm{RV}$; writing (original draft preparation): $\mathrm{CB}$; writing (review and editing including critical revision of manuscript for important intellectual content): $\mathrm{CB}, \mathrm{KD}, \mathrm{PC}, \mathrm{ND}, \mathrm{RV}$.

Open Access This article is licensed under a Creative Commons Attribution-NonCommercial 4.0 International License, which permits any non-commercial use, sharing, adaptation, distribution and reproduction in any medium or format, as long as you give appropriate credit to the original author(s) and the source, provide a link to the Creative Commons licence, and indicate if changes were made. The images or other third party material in this article are included in the article's Creative Commons licence, unless indicated otherwise in a credit line to the material. If material is not included in the article's Creative Commons licence and your intended use is not permitted by statutory regulation or exceeds the permitted use, you will need to obtain permission directly from the copyright holder. To view a copy of this licence, visit http://creativecommons.org/licenses/by-nc/4.0/.

\section{References}

1. Pharmaceutical Benefits Advisory Committee. Guidelines for preparing submissions to the Pharmaceutical Benefits Advisory Committee. Version 5.0, Canberra, 2016. Available from: https:// pbac.pbs.gov.au/content/information/printable-files/pbacg-book. pdf. Accessed 01 Sept 2021

2. National Institute for Health and Care. Guide to the methods of technology appraisal. London, 2018. Available from: https://www. nice.org.uk/guidance/GID-NG10013/documents/draft-guideline. Accessed 20 May 2021

3. Wolstenholme JL, Bargo D, Wang K, Harnden A, Räisänen U, Abel L. Preference-based measures to obtain health state utility values for use in economic evaluations with child-based populations: a review and UK-based focus group assessment of patient and parent choices. Qual Life Res. 2018;27(7):1769-80. https:// doi.org/10.1007/s11136-018-1831-6.

4. Rowen D, Rivero-Arias O, Devlin N, Ratcliffe J. Review of valuation methods of preference-based measures of health for economic evaluation in child and adolescent populations: where are we now 
and where are we going? Pharmacoeconomics. 2020;38(4):32540. https://doi.org/10.1007/s40273-019-00873-7.

5. Shah KL, Ramos-Goñi JM, Kreimeir S, Devlin NJ. Anchoring latent scale values for the EQ-5D-Y at 0 = Dead. London, 2020. Available from: https://www.ohe.org/publications/anchoringlatent-scale-values-eq-5d-y-0-dead\#. Accessed 22 Oct 2021.

6. Petrou S. Methodological issues raised by preference-based approaches to measuring the health status of children. Health Econ. 2003;12(8):697-702. https://doi.org/10.1002/hec.775.

7. Department of Health; Australian Government. The Pharmaceutical Benefits Scheme (PBS), 2020. Available from: https://www. pbs.gov.au/pbs/home;jsessionid=1sxoujb4jac421mk7p7pjk4f8e. Accessed 22 Oct 2021.

8. Department of Health; Australian Government. The Pharmaceutical Benefits Scheme: Public Summary Documents by product, 2021. Available from: https://www.pbs.gov.au/pbs/industry/listi ng/elements/pbac-meetings/psd/public-summary-documents-byproduct. Accessed 20 May 2021.

9. The Pharmaceutical Benefits Advisory Committee. PBAC guidelines; Section 3A 1.2, PBAC guidelines, 2016. Available from: https://pbac.pbs.gov.au/section-3a-cost-effectiveness-analysis. html. Accessed 26 Apr 2021.

10. Department of Health. 3A.5 health outcomes, the Pharmaceutical Benefits Scheme guidelines. Australian Government. 2016. Available from: https://pbac.pbs.gov.au/section-3a/3a-5-health-outco mes.html. Accessed 21 June 2021.

11. National Health and Medical Research Council. Medical Research Future Fund: preventive and public health research initiative 2019 targeted health system and community organisation research grant opportunity guidelines. Canberra: 2019.

12. WHO. Executive summary: report of the 22nd WHO Expert Committee on selection and use of essential medicines. WHO Med. 2019;1-15.

13. The Australian Government Department of Social Services. Growing up in Australia; the longitudinal study of Australian children 2012-13 annual report. Canberra: 2012.

14. Department of Health. National immunisation program schedule, 2021. Available from: https://www.health.gov.au/health-topics/ immunisation/immunisation-throughout-life/national-immunisati on-program-schedule. Accessed 22 Mar 2021.
15. Liberati A, Altman D. Tetzlaff J et al. The PRISMA statement for reporting systematic reviews and meta-analyses of studies that evaluate healthcare interventions: explanation and elaboration. BMJ. 2009;339: b2700. https://doi.org/10.1136/bmj.b2700.

16. Torrance GW, Feeny DH, Furlong WJ, Barr RD, Zhang Y, Wang Q. Multiattribute utility function for a comprehensive health status classification system: Health Utilities Index Mark 2. Med Care. 1996;34:702-22.

17. Rabin R, De Charro F. EQ-5D: a measure of health status from the EuroQol Group. Ann Med. 2001;33(5):337-43. https://doi.org/10. 3109/07853890109002087.

18. Richardson J, Day NA, Peacock S, Iezzi A. Measurement of the quality of life for economic evaluation and the assessment of quality of life (AQoL) mark 2 instrument. Aust Econ Rev. 2004;37(1):62-88. https://doi.org/10.1111/j.1467-8462.2004. 00308.x.

19. Yang Y, Brazier JE, Tsuchiya A, Young TA. Estimating a preference-based index for a 5-dimensional health state classification for asthma derived from the asthma quality of life questionnaire. Med Decis Mak. 2011;31(2):281-91. https://doi.org/10.1177/ 0272989X10379646.

20. Australian Government Department of Health. Section 100: highly specialised drugs program, the Pharmaceutical Benefits Scheme, 2019. Available from: https://www.pbs.gov.au/info//browse/secti on-100/s100-highly-specialised-drugs\#: text $=$ Highly Specialised Drugs-, Section 100-Highly Specialised Drugs Program, Drugs Program-(Community Access). Accessed 27 Apr 2021.

21. Prosser L, Ray T, O’Brien M, Kleinman K, Santoli J, Lieu T. Preferences and willingness to pay for health states prevented by pneumococcal conjugate vaccine. Pediatrics. 2004;113(2):283-90.

22. Lee GM, Lett S, Schauer S et al. Societal costs and morbidity of pertussis in adolescents and adults. Clin Infect Dis. 2004;39(11):1572-80. 